\title{
Antimicrobial Activity, DFT Calculations, and Molecular Docking of Dialdehyde Cellulose/Graphene Oxide Film Against Covid-19
}

\author{
Sawsan Dacrory ${ }^{1}$ (D) \\ Accepted: 31 December 2020 / Published online: 17 January 2021 \\ (c) The Author(s), under exclusive licence to Springer Science+Business Media, LLC part of Springer Nature 2021
}

\begin{abstract}
Development of the oxidation process of cellulose has occurred to decrease the reaction time. Dialdehyd cellulose (DAC) has synthesized via periodate oxidation under microwave irradiation and Graphen oxide (GO) was synthesized by modified Hummer method. A new composite of DAC/GO has prepared from GO and DAC. The structure and morphology of DAC, GO and DAC/GO composite were evaluated via Fourier transform infrared spectroscopy, scanning electron microscopy and X-ray diffraction. Mechanical properties of DAC and DAC/GO were investigated. Additionally, the computational calculations of cellulose, DAC and GO by DFT/B3LYP/6-31G (d) basis sets were investigated. DAC/GO composite demonstrated specific antimicrobial activity against Gram-positive and Gram-negative bacteria. The molecular docking of DAC shows binding energy interaction $(-4.1,-4.0$, and -4.0$) \mathrm{Kcal} / \mathrm{mol}$ against microbial protein of Pseudomonas aeruginosa as Gram-negative bacteria PDB (2W7Q), and Staphylococcus aureus as Gram-positive bacteria PDB (1BQB) as well as Covid-19 PDB (7BZ5) respectively. DAC shows drug-like behavior when it is compared with binding energy interaction of Hydroxychloroquine against Covid-19, as a standard drug.
\end{abstract}

Keywords Cellulose $\cdot$ 2,3 Dialdehyde cellulose $\cdot$ Graphen oxide $\cdot$ Antimicrobial activity $\cdot$ Covid-19

\section{Introduction}

A pandemic of coronavirus represents a burden for the entire world that threats the human life. Therefore, scientists try to find suitable drug can stop the viral replication. Graphene oxide $(\mathrm{GO})$ is a new material that holds promising properties due to its unique structure [1]. It is composed of a single layer of graphene bound to oxygen in the form of carboxyl, hydroxyl, or epoxy groups [2,3]. Due to its mechanical, electronic, optical and thermal properties GO has a major role in many applications such as energy storage devices, flexible electronics, sensors and solar cells. [4]. Cellulose is an attractive renewable raw material, non-toxic, biodegradable and biocompatible polymer. Therefore, it has been reported to be a promising material that used in numerous types of applications [5-8]. It has distinctive chemical structure composed of linear chains linked together by $\beta(1 \rightarrow 4)$ linked D-glucose unites [9]. Although it's distinctive

Sawsan Dacrory

sdmali82@yahoo.com

1 Cellulose and Paper Department, National Research Centre, Cairo 12622, Egypt properties, cellulose is insoluble in conventional solvents and it owing to inter and intra-molecular hydrogen bonds which obstacle it's direct reaction. For this reason cellulose needs indispensable modification to improve their properties and to extend the range of their uses [10-12]. Dialdehyde cellulose (DAC) is one of the most widely used and high reactive cellulose derivative [13]. It is synthesized via conventional oxidation process using sodium meta-periodate which makes specific and selective cleavage of the two secondary hydroxyl groups in $\mathrm{C} 2-\mathrm{C} 3$ vicinal hydroxyl groups in glucopyranose unite as in Fig. 1 [14-16].

By this method aldehyde groups are introduced into polysaccharides and serve as useful material that can be used in different application such as adsorption of heavy metal, separation of protein and drug carriers, [7, 17, 18]. For a long time this process has used to produce dialdehyde cellulose, although it requires a long time [19, 20]. It takes place in two steps. First, cellulose reacts with sodium periodate for 4-12 $\mathrm{h}$ then follows by adding excess of ethylene glycol to quench the reaction [21-23]. So, improvement this method to decrease the reaction time became essential issue. Microwave is an eco-friendly method that not only reduces reaction time but also produces a considerable yield 


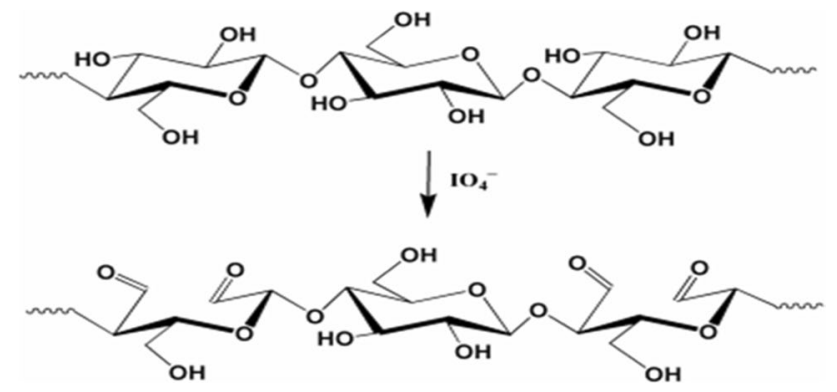

Fig. 1 Oxidation of cellulose

with high quality. Therefore it can be used in organic compounds synthesis [24-26]. In the present study, oxidation process has enhanced by using microwave irradiation in (DAC) synthesis to minimize the reaction time and GO is prepared via modified Hummer method. The structure and morphology of DAC, GO and DAC/GO composite were studied by (FTIR), (SEM) and (XRD). Mechanical properties of DAC and DAC/GO were investigated. Additionally, the computational calculations of cellulose and CDA by DFT/ B3LYP/6-31G (d) basis sets were investigated. Antimicrobial activity of DAC and DAC//GO composite against Gram-negative bacteria and Gram-positive bacteria was investigated. Also, molecular docking of DAC to show its interaction with microbial protein of Pseudomonas aeruginosa PDB (2W7Q), and Staphylococcus aureus PDB (1BQB) as well as with covid-19 PDB (7BZ5) was studied and compared with Hydroxychloroquine as a standard drug used against Covid-19.

\section{Experimental}

\section{Materials}

Cellulose was purchased from Loba Chem. And sodium periodate was purchased from Analytical Rasayan, Graphite (G) powder (99.9\%) was provided by Fisher Scientific UK. Potassium permanganate ( $>99 \%)$ and hydrogen peroxide (30\%) were bought from Bio Basic Canada Inc. and Carl Roth $\mathrm{GmbH}$, respectively. Sodium nitrate (99.99\%) was supplied by Sd Fine-CHEM limited (India). All chemical and, reagents used were in analytical grade without any purification required before use.

\section{Synthesis of Dialdehyde Cellulose (DAC)}

Cellulose was oxidized with sodium periodate to different degrees of oxidation by microwave assistant as a new method. Briefly, $1.5 \mathrm{~g}$ of cellulose was dispersed in $20 \mathrm{ml}$ distilled water. Then different ratios of sodium periodate were added $(1,2$, and $3 \mathrm{~g})$. Precursor was transferred to the microwave oven to complete the oxidation process at three different times $(0.5,1$ and $1.5 \mathrm{Min})$. The oxidized product was filtered and washed with ethanol many times then dried overnight at room temperature.

\section{Determination of Aldehyde Content}

Aldehyde content of oxidized cellulose was determined according to Ref [27] by Schiff' base reaction. In which aldehyde groups convert to corresponding oxime using hydroxylamine hydrochloride. $0.3 \mathrm{~g}$ of the DAC sample was dispersed in $20 \mathrm{ml}$ distilled water and the (pH5) by sodium hydroxide solution. Then $20 \mathrm{ml}$ hydroxylamine hydrochloride solution $(0.72 \mathrm{~mol} / \mathrm{l})$ with $\mathrm{pH} 5$ was added. The mixture was stirred at $40{ }^{\circ} \mathrm{C}$ for $4 \mathrm{~h}$. The released hydrochloric acid was titrated by using $1.0 \mathrm{M}$ aqueous sodium hydroxide solution. The amount of $\mathrm{NaOH}$ consumed when the $\mathrm{pH}$ value of the solution reached 5.0 was recorded [22]. The volume of alkali solution consumed in the titration was recorded as Va (in litre). The same concentration of cellulose solution at $\mathrm{pH} 5.0$ was used as a blank and the volume of $1.0 \mathrm{M}$ sodium hydroxide solution consumed was recorded as Vc (in litre). The aldehyde content $(\% \mathrm{w} / \mathrm{w})$ calculated using the following equation $[28,29]$.

$$
\begin{aligned}
& -\mathrm{CHO}+\mathrm{NH}_{2} \mathrm{OH}-\mathrm{HCl} \rightarrow-\mathrm{CHNOH}+\mathrm{HCl}+\mathrm{H}_{2} \mathrm{O} \\
& \mathrm{HCl}+\mathrm{NaOH} \rightarrow \mathrm{NaCl}+\mathrm{H}_{2} \mathrm{O} \\
& \text { Aldehyde Content }(\%)=\frac{C_{\mathrm{NaOH}} \times(\mathrm{Va}-\mathrm{Vc})}{8 \times \mathrm{m} / \mathrm{M}}
\end{aligned}
$$

where $\mathrm{C}_{\mathrm{NaOH}}=1.0 \mathrm{M}, m$ is the dry weight of DAC $(0.3 \mathrm{~g})$ used in the experiment and $M$ molecular weight of the repeating unit of cellulose (162).

\section{Preparation of GO}

In typical procedure, graphene oxide (GO) was produced using modified hummer method from pure graphite powder. In this method, $27 \mathrm{ml}$ of sulfuric acid $\left(\mathrm{H}_{2} \mathrm{SO}_{4}\right)$ and $3 \mathrm{ml}$ of phosphoric acid $\left(\mathrm{H}_{3} \mathrm{PO}_{4}\right)$ (volume ratio 9:1) were mixed and stirred for several minutes. Then $0.225 \mathrm{~g}$ of graphite powder was added into mixing solution under stirring condition. $1.32 \mathrm{~g}$ of potassium permanganate $\left(\mathrm{KMnO}_{4}\right)$ was then added slowly into the solution. This mixture was stirred for $6 \mathrm{~h}$ until the solution became dark green. To eliminate excess of $\mathrm{KMnO}_{4}, 0.675 \mathrm{ml}$ of hydrogen peroxide $\left(\mathrm{H}_{2} \mathrm{O}_{2}\right)$ was dropped slowly and stirred for $10 \mathrm{~min}$. The exothermic reaction occurred and let it to cool down. $10 \mathrm{ml}$ of hydrochloric acid $(\mathrm{HCl})$ and $30 \mathrm{ml}$ of deionized water (DIW) was added and centrifuged at $5000 \mathrm{rpm}$ for $7 \mathrm{~min}$. Then, the supernatant was decanted away and the 
residuals were then rewashed again with $\mathrm{HCl}$ and DIW for 3 times. The washed GO solution was dried using oven at $90{ }^{\circ} \mathrm{C}$ for $24 \mathrm{~h}$ to produce the powder of GO [30].

\section{Preparation of DAC/GO Film}

DAC film was prepared with and without GO by casting method [31]. In $250 \mathrm{ml}$ bottle reagent $1 \mathrm{~g}$ of DAC was dispersed in $20 \mathrm{ml}$ deionized water. $0.05 \mathrm{~g}$ of prepared $\mathrm{GO}$ is added with continues stirring. Then $10 \mathrm{ml} \mathrm{PVA} \mathrm{(5 \%} \mathrm{w/v)} \mathrm{and}$ $1 \mathrm{ml}(25 \% \mathrm{w} / \mathrm{v})$ glycerol were added. A homogenous solution obtained by ultra-sonication for $2 \mathrm{~min}$. in an ice bath the solution was poured onto a Teflon plate and left to dry at room temperature.

\section{Characterization}

FT-IR spectra of cellulose and DAC were recorded in the range of $400-4000 \mathrm{~cm}^{-1}$ on (Shimadzu 8400 S) FT-IR Spectrophotometer. The surface morphology of cellulose, DAC and DAC/ GO film were analyzed using electron microscope FEI IN SPECTS Company, Philips, Holland, environmental scanning without coating. The crystallinity of cellulose, DAC, GO and $\mathrm{DAC} / \mathrm{GO}$ were detected using an X-ray diffractometer. $\mathrm{X}$-ray diffraction patterns were obtained using a Brukur D8 Advance X-ray diffract meter (Germany). The diffraction patterns were recorded using copper $(\mathrm{K} \alpha)$ target with a secondary monochromatic at $40 \mathrm{kV}$ and $40 \mathrm{~mA}$. The crystallinity index (CrI) was defined according to [6].

$\mathrm{C}_{\mathrm{r}} \mathrm{I} \%=\left(\mathrm{I}_{002}-\mathrm{I}_{\mathrm{am}}\right) / \mathrm{I}_{002} \times 100$

where $\mathrm{I}_{002}$ is the maximum intensity of 002 lattice diffraction at $2 \theta=21-23$ and Iam is the intensity of diffraction in the same unite at $2 \theta=18^{\circ}$. The stress-strain curve of the DAC, and DAC/GO composite film were measured on $6 \mathrm{~cm}$ film strips (width $15 \mathrm{~mm}$; length $20 \mathrm{~mm}$ ) using a Lloyd instrument (Lloyd Instruments, West Sussex, United Kingdom (with a 5-N load cell measurements were made at room temperature [31].

\section{Computational Procedures}

Calculations of Density Functional Theory (DFT) with a hybrid functional B3LYP (Becke's three-parameter hybrid functional using the BLYP correlation functional) with the 6-31G(d) basis set exhausting the Berny method were performed with the Gaussian 09 W program [31, 32].

\section{Molecular Modeling and Docking}

The molecular modeling of Pseudomonas aeruginosa (NCID-9016) as Gram-negative bacteria PDB (2W7Q),
Staphylococcus aureus (NCTC-7447) as Gram-positive bacteria PDB (1BQB) and Covid-19 (7BZ5) with DAC was fabricated using standard bond lengths and angles, with the Auto Dock Vina and detected by Discovery Studio Client (version 4.2) [32]

\section{Antimicrobial Study}

The antimicrobial test was carried out via the plat diffusion method according to previous [13,31,33] studies with about $0.2 \mathrm{gm}$ of DAC and DAC/GO individual. Five microorganisms are tested against conjugate Bacillus subtilis (NCID3610) and Staphylococcus aureus (NCTC-7447) as Grampositive bacteria, and, Escherichia coli (NCTC-10416) and Pseudomonas aeruginosa (NCID-9016) as Gram-negative bacteria as well as Candida albicans (NCCLS 11) were used. One colony of each microbial strain was suspended in a physiological saline solution $(\mathrm{NaCl} 0.9 \%$ in distilled water at $\mathrm{pH} 6.5$ ).

\section{Result and Discussion}

\section{Synthesis of Dialdehyde Cellulose (DAC)}

Dialdehyde cellulose is successfully prepared by sodium periodat oxidation via microwave irradiation, which produced selective cleavage of the two secondary hydroxyl groups in C2-C3 vicinal hydroxyl groups in glucopyranose unite in cellulose chains; giving ring-opened product with dialdehyde groups as in Fig. 2a. In this method large numbers of dialdehyed introduced in cellulose chain with high selectivity and high yield [27].

Aldehyde content (AC) represents the oxidation degree (the percentage of monosaccharide units which reacted with periodate) [27]. Table 1. shows the effect of periodate dosage and the reaction time on aldehyde content $\mathrm{AC}$ which increased according to periodate dosage increased to reach high value $63 \%$ with high yield $98 \%$ this result agree with previous result reported by [28]. On the other hand, aldehyde content increased with the reaction time increased to reach high value $63 \%$ with yield $85 \%$ then started decrease. It may be due to increasing hemiacetal bonds which act as protecting group toward periodate oxidation [15].

\section{FT-IR Analysis}

FTIR of cellulose and DAC were displayed in Fig. 2b. In a comparison between cellulose and DAC spectra found that, cellulose showed adsorption bands of $\mathrm{OH}$ stretching at $3000-3500 \mathrm{~cm}^{-1}$, and $\mathrm{CH}$ stretching at $2900 \mathrm{~cm}^{-1}$, these peaks became narrow and deceased in DAC spectra [34]. The peak at $1640 \mathrm{~cm}^{-1}$ represents the $\mathrm{OH}$ bending 
A

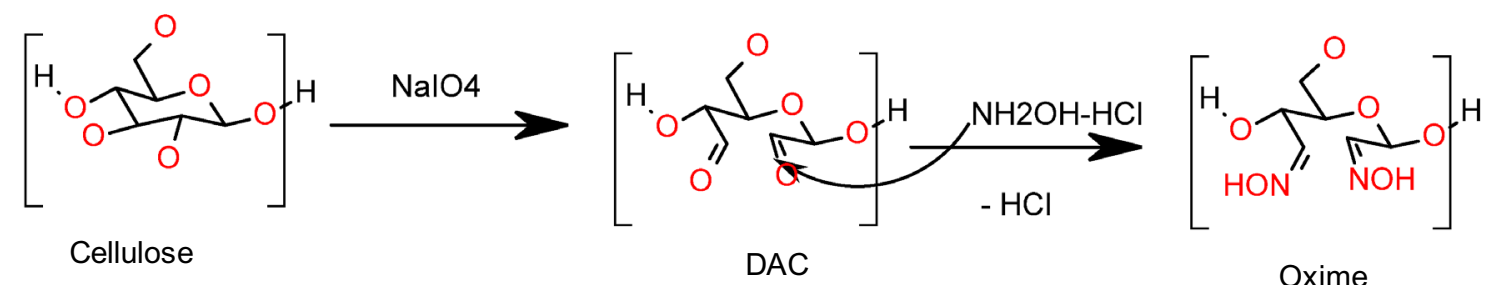

Cellulose

DAC

Oxime

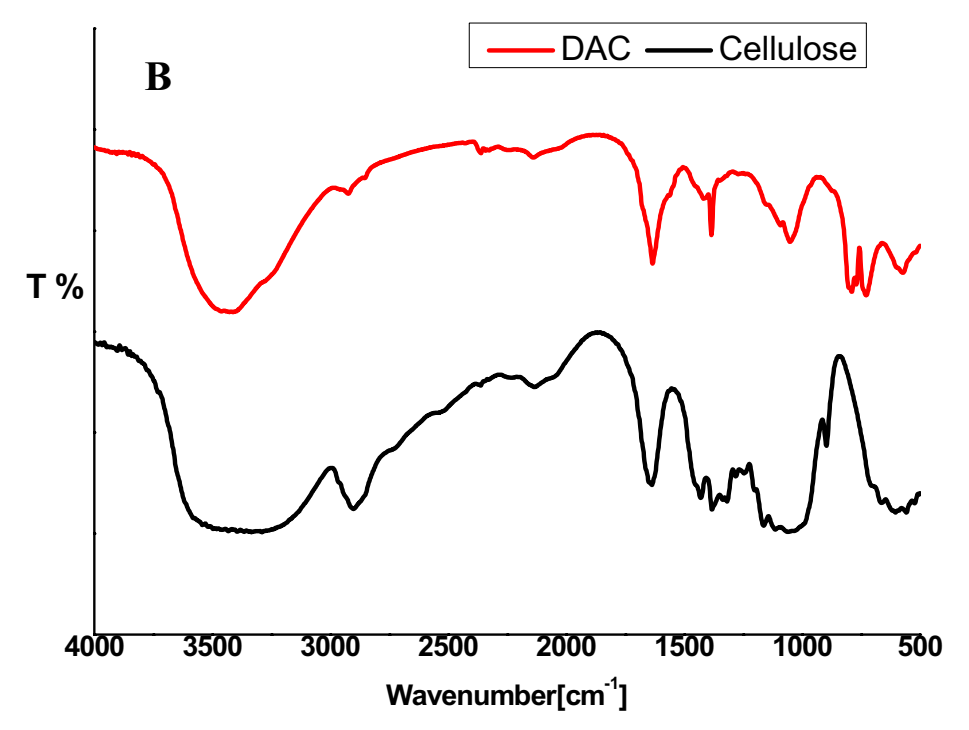

Fig. 2 a Synthesis of DAC, b FTIR of cellulose and DAC

Table 1 Effect of time and $\mathrm{NaIO}_{4}$ on aldehyde content $\mathrm{AC}$

\begin{tabular}{llllll}
\hline Time & Yield $\%$ & $\mathrm{AC} \%$ & $\mathrm{NaIO}_{4}$ & Yield & $\mathrm{AC} \%$ \\
\hline $0.5 \mathrm{Min}$ & 30 & 48 & $1 \mathrm{~g}$ & 28 & 27 \\
1.0 Min & 85 & 63 & $2 \mathrm{~g}$ & 52 & 63 \\
$1.5 \mathrm{Min}$ & 92 & 37 & $3 \mathrm{~g}$ & 98 & 63 \\
\hline
\end{tabular}

of the adsorbed water in cellulose [13] while the peak at $1650 \mathrm{~cm}^{-1}$ in DAC spectrum represents the carbonyl group $\mathrm{C}=\mathrm{O}$ of dialdehyde [35] sometimes this peak can be very small and hidden due to presence DAC in hydrated form but presence of hemiacetal peak confirms DAC formation [36]. Adsorption bands of $\mathrm{CH}_{2}$ bending vibrations and $\mathrm{C}-\mathrm{O}-\mathrm{C}$ at $1380 \mathrm{~cm}^{-1}$ and $1040 \mathrm{~cm}^{-1}$ respectively, decreased in DAC due to degradation of cellulose [13,
33]. In DAC spectra a new adsorption band at 800-750 corresponding to hemiacetal bond which is a characteristic peak of aldehyde [14, 27]. This bond formed between newly aldehyde groups and their adjacent hydroxyl groups $\mathrm{OH}$ [37].

\section{Preparation of G0}

GO has synthesized by modified Hummer method oxidation. Through this method, multi layers of graphite converted to mono-layer with new groups such as carbonyl, carboxylic, and hydroxyl that incorporated in GO matrix as in Fig. 3a. As shown in Fig. 3b, XRD has used to investigate the formation of GO from graphite which has distinctive peak at $2 \theta=26$, while GO has a characteristic peak at $2 \theta=10$ due to new groups formation which confirms successful oxidation of graphite [38, 39]. 
A

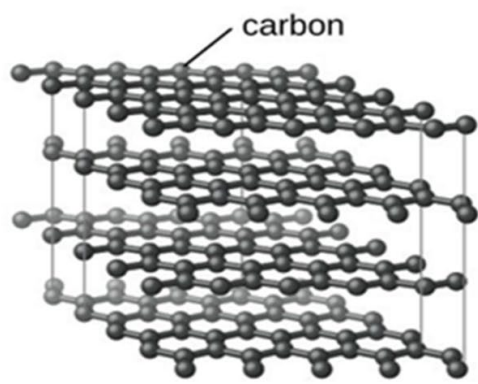

graphite

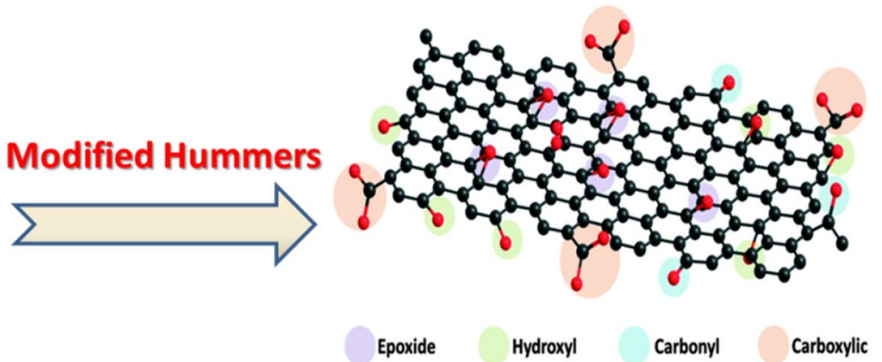

GO

B

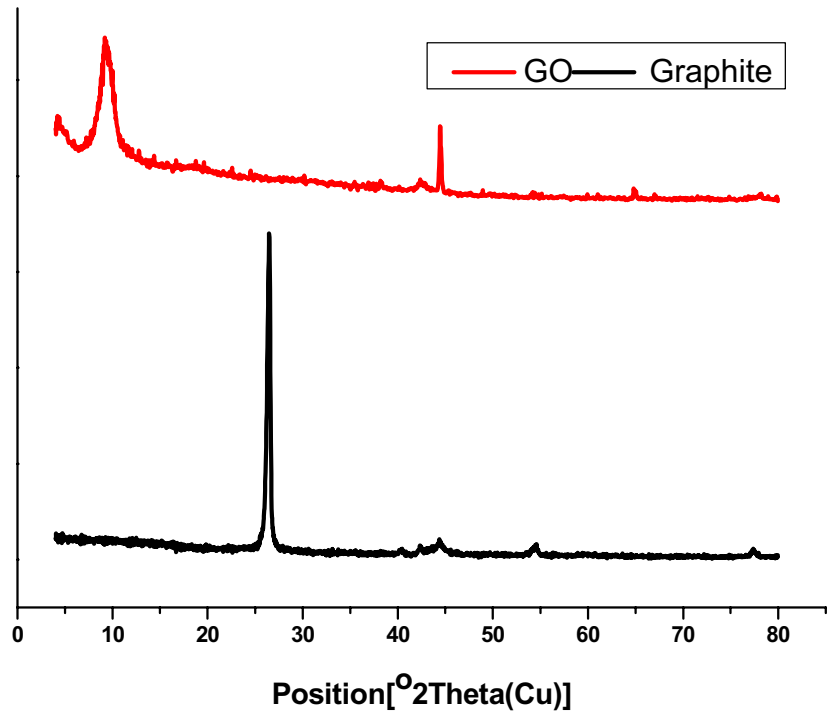

Fig. 3 a Synthesis of GO by modified Hummer method, b XRD of graphite and GO

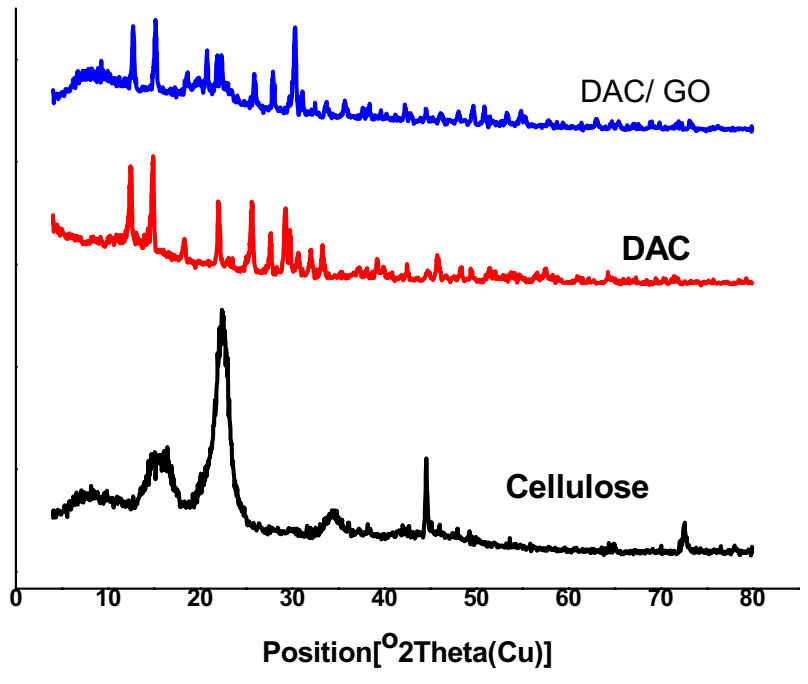

Fig. 4 XRD of cellulose, DAC and DAC/GO

\section{X-Ray Diffraction}

Cellulose has amorphous and crystalline regions at (20) $15,22^{\circ}$ respectively. Figure 4 represents the effect of the oxidation process on crystallinity of cellulose. A complete degradation occurred for cellulose chains, therefore the crystallinity decreased from $85 \%$ in cellulose to $45 \%$ in DAC as well as the structure of cellulose changed according to the oxidation. The broad peak at (20) $20-23^{\circ}$ which represents the crystallinity region in cellulose decreased in DAC [36]. The loss of crystallinity is due to the ring-opened formation of the glucopyranose units and destruction of their backbone. These results agree with a similar XRD pattern for natural oxidized polysaccharide was reported by $[17,27$, 28]. After loading GO on DAC matrix, the peak at $2 \theta=10$ of GO disappeared. It was noticed that the crystallinity of DAC slightly changed by incorporation of GO [40]. 
Fig. 5 a SEM of cellulose, DAC and DAC/GO, b Stress/ strain curve of DAC and DAC/GO
A
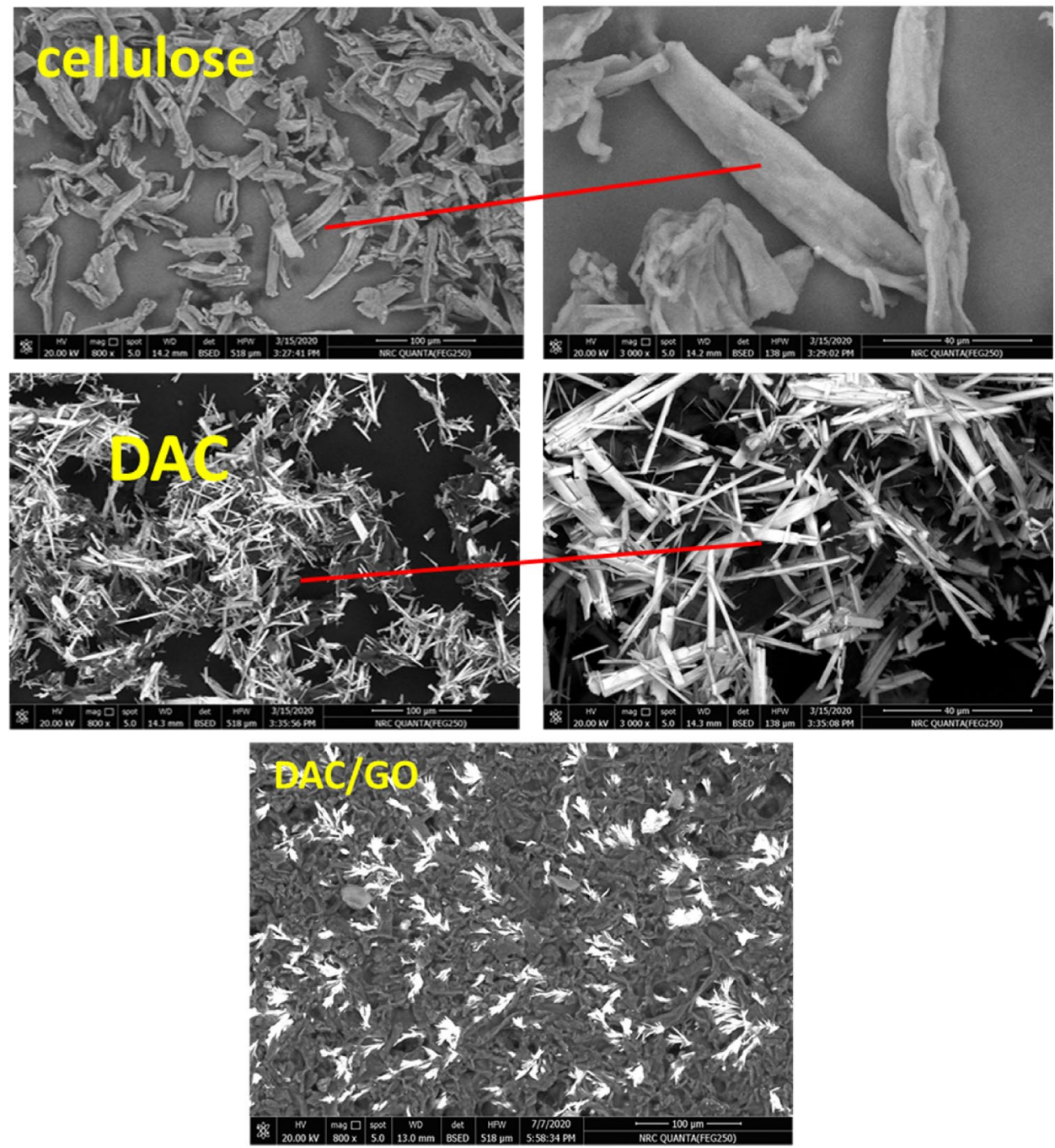

B

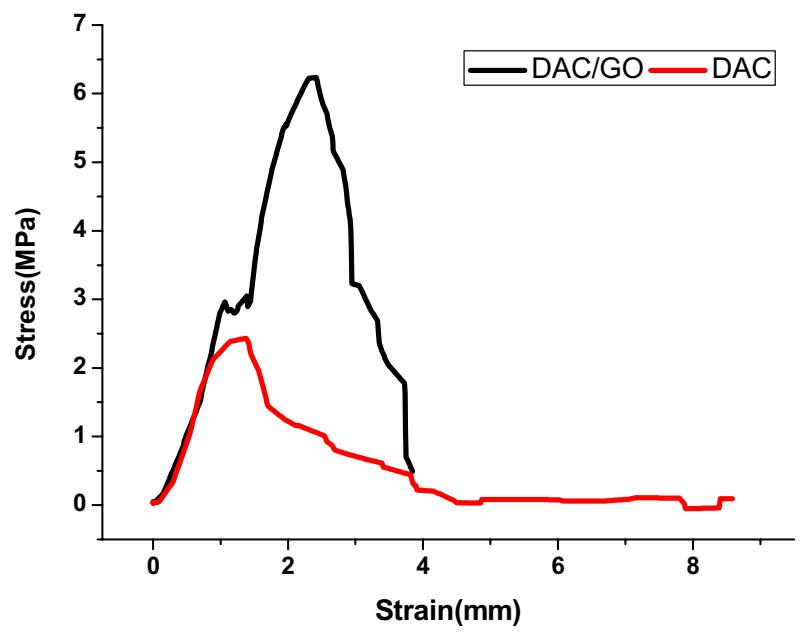




\section{Scanning Electron Microscopy (SEM)}

Figure 5a shows the surface morphology of cellulose and DAC, and how the oxidation process affected on cellulose surface morphology and their ordered structure. The surface morphology of cellulose changed after oxidation process. As it seems in Fig. 5 the backbone structure of cellulose is destroyed as a result of the ring-opened formation. In SEM images, cellulose fibers appear as large and long fragments, while DAC appears as small and short fragments due to the degradation process $[17,28]$. DAC/GO image represents homogenous surface incorporated with GO that looks clustered on the entire surface [30].

\section{Mechanical Properties}

Tensile strength and elongation at break of DAC and DAC/ GO film were investigated at room temperature. Figure $5 \mathrm{~b}$ shows stress/strain curve that shows softness and hardness of the films. DAC/GO film has tensile strength (stress) of 6.5 Mpa more than DAC which has tensile strength of $2.2 \mathrm{Mpa}$ and it returns to decrease crystallinity of DAC due to oxidation process and destruction of the chains backbone. This confirms that GO improve tensile strength by forming hydrogen bonds with DAC [40].

\section{Computational Procedures}

Optimized geometries of cellulose, DAC as a monomer and GO were calculated by DFT B3LYP/6-31G (d) bases site. Figure 6a shows the molecular structure of cellulose and DAC are not planer. And DAC molecular structure changed as a result of periodate oxidation due to ring-opened and backbone destruction. Table 2 shows some parameters reflect the reactivity and the stability of molecules such as total energy $\mathrm{E}_{\mathrm{T}}$, energy of highest occupied (electron donating) MO EHOMO, energy of lowest unoccupied (electron accepting) MO ELUMO, energy gap (Eg). GO and DAC are more reactive than cellulose due to low absolute hardness $(\eta)$ and high absolute softness $(\sigma)$ due to oxidation process [41] based on dipole moment $(\mu)$, absolute electronegativity's $(\chi)$ and chemical potentials $(\mathrm{Pi})$ values. Also global electrophilicity $(\omega)$, and additional electronic charge, $(\Delta \mathrm{Nmax})$ are calculated using the following equations [31, 32].

$\Delta E=E_{L U M O}-E_{\text {HOMO }}$

$\chi=\frac{-\left(E_{\text {HOMO }}+E_{L U M O}\right)}{2}$
$\eta=\frac{\left(E_{L U M O}-E_{H O M O}\right)}{2}$

$\sigma=1 / \eta$

$\mathrm{Pi}=-\mathrm{X}$

$\omega=\mathrm{Pi}^{2} / 2$

$\Delta \mathrm{N}_{\max }=-\mathrm{Pi} / \eta$

Figure 6b Shows frontier molecular orbital, which is a guide principle for chemical and physical properties of molecule [42]. As the energy gap (Eg) decrease the reactivity of molecule increase and it can be excited easily with small energy [43]. The energy gap (Eg) between electron donating molecular orbital HOMO and electron accepting molecular orbital LUMO connected to the biological activity and stability of compounds. Since DAC, GO show a biological activities, therefore, the investigation of the different conformational structures of DAC, GO is important for drug design and to understand the several medicinal effects [44]. As in Table 2 energy gap (Eg) of GO is less than energy gap (Eg) of DAC and cellulose which makes GO more reactive than DAC and cellulose [32, 43]

\section{Molecular Modeling and Docking}

Figure 7a shows plausible interaction sites of DAC to bind in active pocket of protein. Molecular docking shows DAC acts as a ligand with microbial protein that acts as a receptor, Pseudomonas aeruginosa as Gram-negative bacteria PDB (2W7Q) 7b, and Staphylococcus aureus as Grampositive bacteria PDB (1BQB) 7c as well as with covid19 PDB (7BZ5) 7d. Wherein docking of protein-ligand the hydrogen bonds interaction confirmed hydrophobic interaction between hydroxyl group $\mathrm{OH}$ and $\mathrm{C}=\mathrm{O}$ of $\mathrm{DAC}$ with $\mathrm{NH}$ group of amino acid protein with excellent confirmation interaction energy score $(-4.1,-4.0,-4.0)$ $\mathrm{Kcal} / \mathrm{mol}$ and short bond length $(1.5 \AA, 1.07 \AA, 1.2 \AA)$ respectively. Hydroxychloroquine $7 \mathrm{E}$ is a standard drug used for Covid-19, shows binding energy (-3.6) Kcal/ mol with short bond length $(1.4 \AA)$ with covid-19 PDB (7BZ5) more than DAC. The result suggests that DAC has drug-like behavior. 
Fig. 6 a The optimized geometry and numbering system of cellulose, DAC and GO. b Gap energy (HOMO-LUMO) (eV) for cellulose, DAC and GO usingDFTB3LYP/6-31G (d)
A
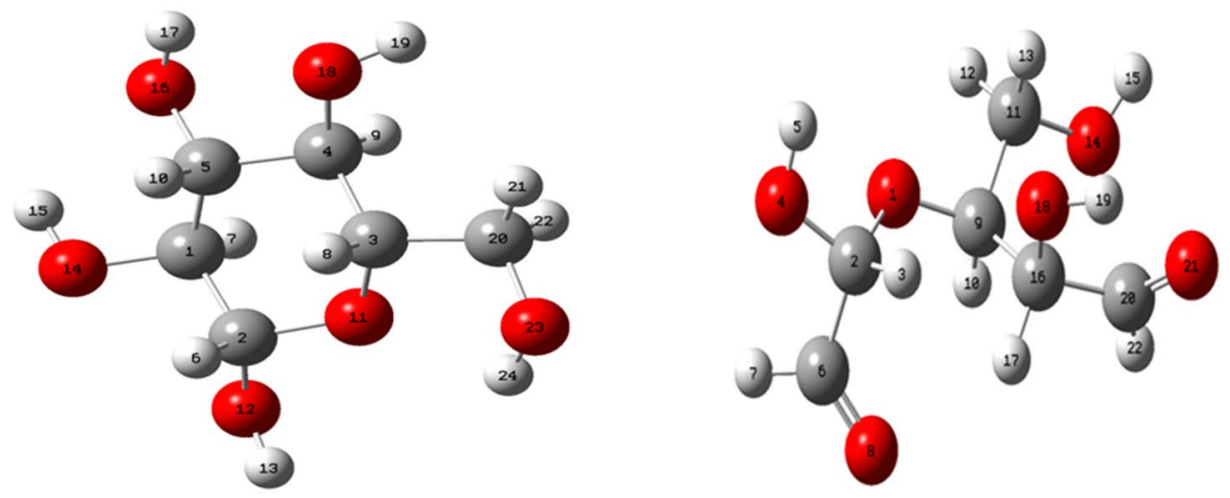

Cellulose

DAC

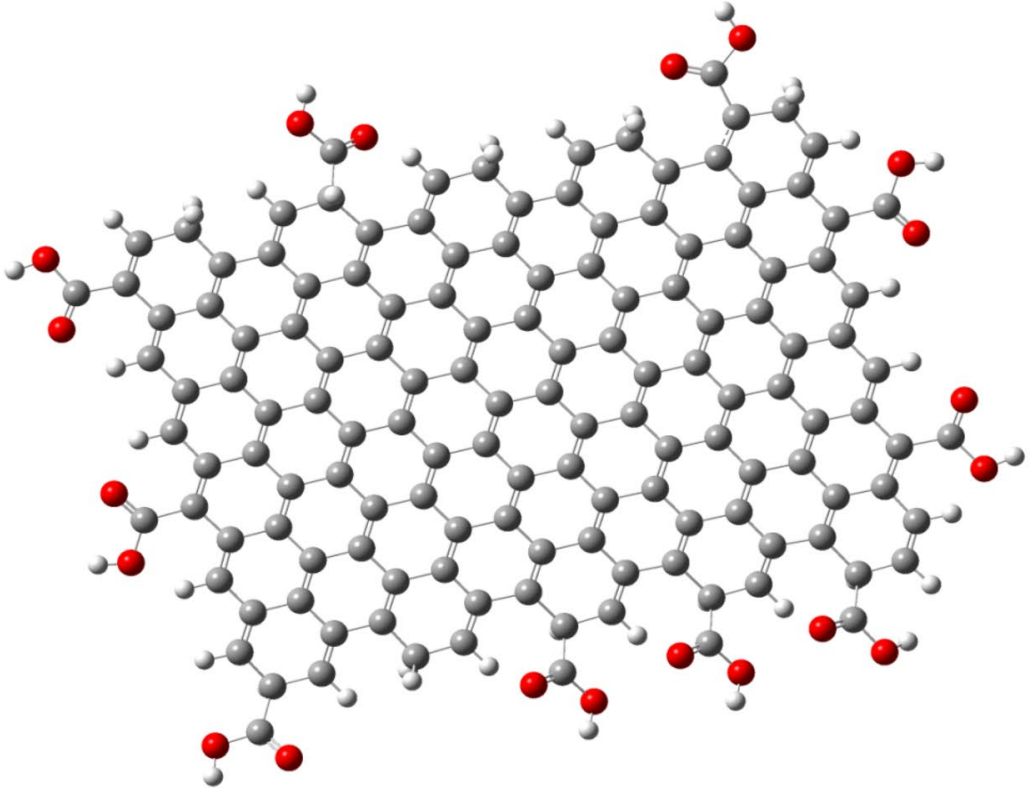

GO 
Fig. 6 (continued)

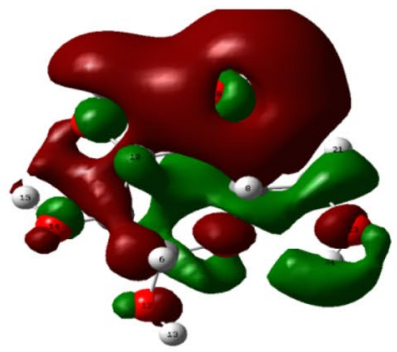

LUMO cellulose
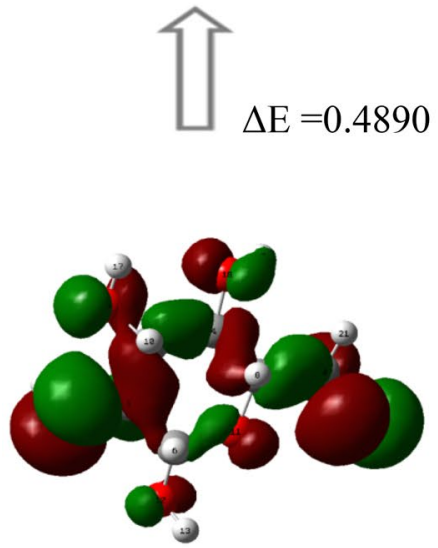

HOMO cellulose

\section{B}

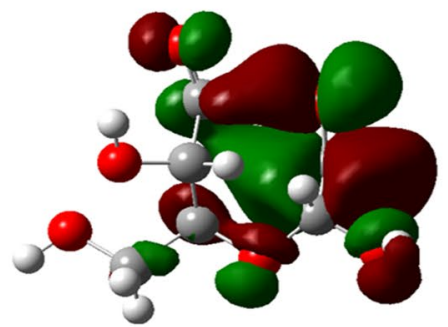

LUMO DAC
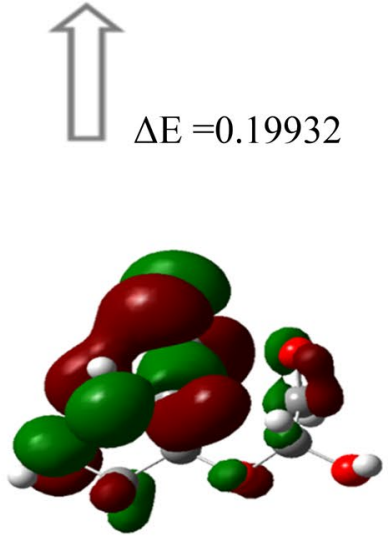

HOMO DAC

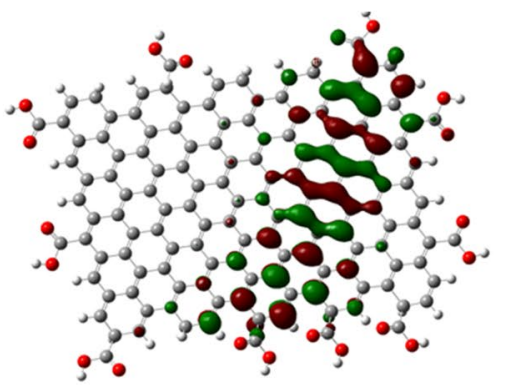

LUMO GO
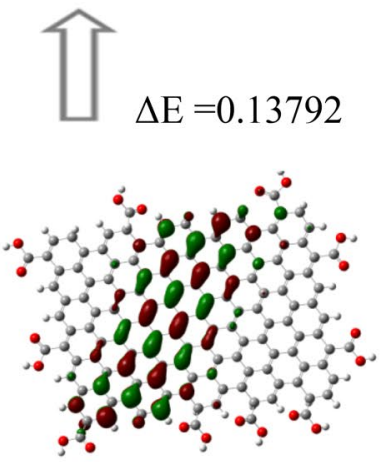

HOMO GO 
Table 2 Optimized geometries of cellulose, DAC and GO

\begin{tabular}{|c|c|c|c|}
\hline \multicolumn{2}{|l|}{ Cellulose } & \multirow{2}{*}{$\begin{array}{l}\text { DAC } \\
\text { DFT B3LYP/6- } \\
31 \mathrm{G}(\mathrm{d})\end{array}$} & \multirow{2}{*}{$\begin{array}{l}\text { GO } \\
\text { DFT B3LYP/6- } \\
31 \mathrm{G}(\mathrm{d})\end{array}$} \\
\hline \multicolumn{2}{|c|}{ DFT B3LYP/6-31G(d) } & & \\
\hline$E_{\mathrm{T}}(\mathrm{au})$ & -686.9304 & -685.6978 & -6784.777 \\
\hline $\mathrm{E}_{\text {номо }}(\mathrm{eV})$ & -0.26945 & -0.26238 & -0.17515 \\
\hline $\mathrm{E}_{\text {LUMO }}(\mathrm{ev})$ & 0.2196 & -0.06306 & -0.03723 \\
\hline$\Delta \mathrm{E}(\mathrm{ev})$ & 0.4890 & 0.19932 & 0.13792 \\
\hline$\mu$ (Debye) & 2.4859 & 2.5890 & 6.8649 \\
\hline$\chi(\mathrm{eV})$ & 0.0249 & 0.16272 & 0.10619 \\
\hline$\eta(\mathrm{eV})$ & 0.2445 & 0.09966 & 0.06896 \\
\hline$\sigma(\mathrm{eV})$ & 4.0895 & 10.0341 & 14.5011 \\
\hline $\mathrm{Pi}(\mathrm{eV})$ & -0.0249 & -0.16272 & -0.10619 \\
\hline$\omega(\mathrm{eV})$ & 0.00127 & 0.1328 & 0.08175 \\
\hline$\Delta \mathrm{N} \max$ & 0.1019 & 1.6327 & 1.5398 \\
\hline
\end{tabular}

\section{Antimicrobial Activity}

Figure 8 illustrates the antimicrobial activity of DAC and DAC/GO. The results show that DAC inhibited the growth of both Gram-positive bacteria and Gram-negative bacteria and it is attributed to dialdehyde group formation [29]. There are two mechanisms for antimicrobial activity. The first is the reactive oxygen species (ROS) where $\mathrm{O}_{2}$ release from $\mathrm{DAC}$ and $\mathrm{GO}$ then reacts with thiol -SH group in protein and forms $\mathrm{H}_{2} \mathrm{O}_{2}$ that can form radical and destroy microbe membrane [31]. The second mechanism is the hydrogen bond formation between DAC and GO with bacterial protein.
This interaction leads to damage cytoplasmic membrane and destroy the protein due to prevent the nutrient uptake process of the bacterial cell [45].

\section{Conclusion}

Conventional oxidation process has improved and reaction time has decreased. Dialdehyde cellulose (DAC) has successfully synthesized for the first time under microwave irradiation with high yield and high aldehyde content (AC) reached to $98 \%$ and $63 \%$, respectively. GO has successfully synthesized via modified Hummer method. As well as DAC/ GO composite has prepared and showed antimicrobial activity against Gram-positive and Gram-negative bacteria. DAC, GO and DAC/GO have characterized via FTIR, SEM and XRD. Mechanical properties of DAC and DAC/GO were investigated and the results showed that GO improved tensile strength (stress) of $6.5 \mathrm{Mpa}$ of the composite. Additionally, the computational calculations of cellulose, DAC and GO by DFT/ B3LYP/6-31G (d) basis sets were investigated. Also, the molecular docking of DAC show strong interaction with microbial protein of Pseudomonas aeruginosa as Gram-negative bacteria PDB(2W7Q), and Staphylococcus aureus as Gram-positive bacteria PDB (1BQB) as well as with Covid-19 PDB (7BZ5) with excellent confirmation interaction energy score $(-4.1,-4.0,-4.0) \mathrm{Kcal} / \mathrm{mol}$ with short bond length $(1.5 \AA, 1.07 \AA, 1.2 \AA)$ respectively. The result suggests that DAC has drug-like behavior. 
Fig. 7 a Interaction side of

DAC with protein, b DAC binding with protein $\mathrm{PDB}(2 \mathrm{~W} 7 \mathrm{Q})$,

c DAC binding with protein

PDB (1BQB), d DAC binding

with protein $\mathrm{PDB}(7 \mathrm{BZ5})$ and

e Hydroxychloroquine binding

with protein $\mathrm{PDB}(7 \mathrm{BZ} 5)$
A

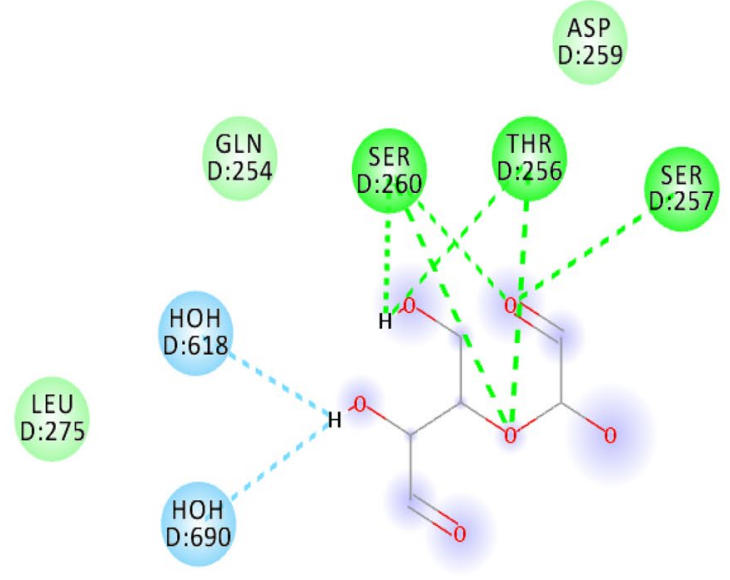

B

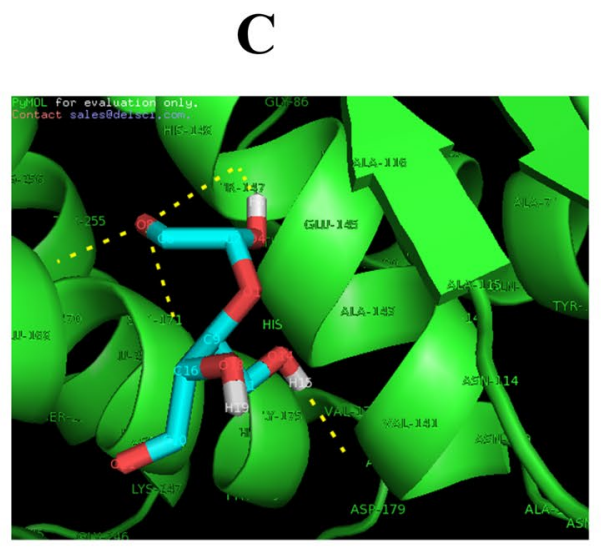

D

E

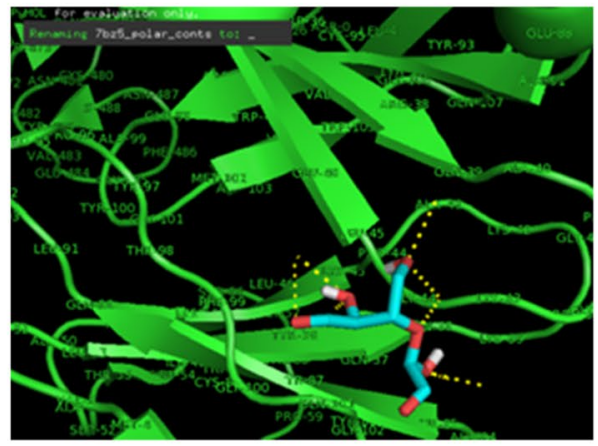




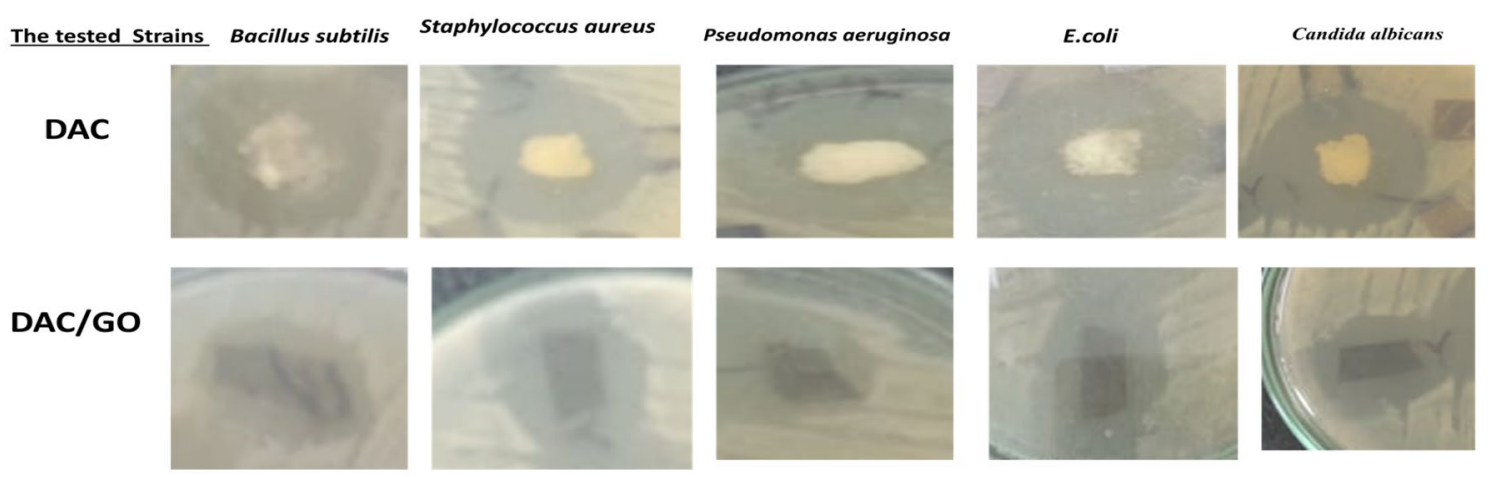

Fig. 8 Antimicrobial activity of DAC and DAC/GO

Acknowledgement The author acknowledges the National Research Center, Egypt and Academy of Scientific Research and Technology (ASRT), Egypt for the financial support.

\section{Compliance with Ethical Standards}

Conflict of interest The authors declare that they have no conflict to interests.

\section{References}

1. Ghanem AF, Abdel Rehim MH (2018) Assisted tip sonication approach for graphene synthesis in aqueous dispersion. Biomedicines 6:63

2. Hazra SK, Basu S (2016) Graphene-oxide nano composites for chemical sensor applications. J Carbon Res 2:12

3. Kapitanova O, Panin G, Baranov A, Kang T (2012) Synthesis and properties of graphene oxide/graphene nanostructures. J Korean Phys Soc 60:1789-1793

4. Krishnamoorthy K, Umasuthan N, Mohan R, Lee J, Kim S-J (2012) Antibacterial activity of graphene oxide nanosheets. Sci Adv Mater 4:1111-1117

5. Abou-Zeid RE, Dacrory S, Ali KA, Kamel S (2018) Novel method of preparation of tricarboxylic cellulose nanofiber for efficient removal of heavy metal ions from aqueous solution. Int J Biol Macromol 119:207-214

6. Dacrory S, Abou-Yousef H, Kamel S, Turky G (2019) Development of biodegradable semiconducting foam based on microfibrillated cellulose/cu-nps. Int J Biol Macromol 132:351-359

7. Kamala KH, Dacroryb S, Alic SS, Alid KA, Kamelb S (2019) Adsorption of $\mathrm{Fe}$ ions by modified carrageenan beads with tricarboxy cellulose: kinetics study and four isotherm models. Desalin Water Treat 165:281-289

8. Sirviö J, Liimatainen H, Niinimäki J, Hormi O (2011) Dialdehyde cellulose microfibers generated from wood pulp by millinginduced periodate oxidation. Carbohyd Polym 86:260-265

9. Dacrory S, Haggag ESA, Masoud AM, Abdo SM, Eliwa AA, Kamel S (2020) Innovative synthesis of modified cellulose derivative as a uranium adsorbent from carbonate solutions of radioactive deposits. Cellulose 27:7093-7108

10. Khattab TA, Dacrory S, Abou-Yousef H, Kamel S (2019) Development of microporous cellulose-based smart xerogel reversible sensor via freeze drying for naked-eye detection of ammonia gas. Carbohyd Polym 210:196-203

11. Khattab TA, Dacrory S, Abou-Yousef H, Smart KS (2019) microfibrillated cellulose as swab sponge-like aerogel for real-time colorimetric naked-eye sweat monitoring. Talanta 205:120166

12. Akl EM, Dacrory S, Abdel-Aziz MS, Kamel S, Fahim AM (2020) Preparation and characterization of novel antibacterial blended films based on modified carboxymethyl cellulose/phenolic compounds. Polym Bull. https://doi.org/10.1007/s00289-020-03148 $-\mathrm{W}$

13. Dacrory S, Abou-Yousef H, Abouzeid RE, Kamel S, Abdel-aziz MS, El-badry M (2018) Antimicrobial cellulosic hydrogel from olive oil industrial residue. Int J Biol Macromol 117:179-188

14. Dacrory S, Abou-Yousef H, Kamel S, Abou-Zeid RE, AbdelAziz MS, Elbadry M (2019) Functionalization and cross-linking of carboxymethyl cellulose in aqueous media. Cell Chem Technol 53(1-2):23-33

15. Plappert SF, Quraishi S, Pircher N, Mikkonen KS, Veigel S, Klinger KM, Potthast A, Rosenau T, Liebner FW (2018) Transparent, flexible, and strong 2,3-dialdehyde cellulose films with high oxygen barrier properties. Biomacromol 19:2969-2978

16. Yang H, Chen D, van de Ven TG (2015) Preparation and characterization of sterically stabilized nanocrystalline cellulose obtained by periodate oxidation of cellulose fibers. Cellulose 22:1743-1752

17. Li H, Wu B, Mu C, Lin W (2011) Concomitant degradation in periodate oxidation of carboxymethyl cellulose. Carbohyd Polym $84: 881-886$

18. Jiang X, Yang Z, Peng Y, Han B, Li Z, Li X, Liu W (2016) Preparation, characterization and feasibility study of dialdehyde carboxymethyl cellulose as a novel crosslinking reagent. Carbohyd Polym 137:632-641

19. Lindh J, Carlsson DO, Strømme M, Mihranyan A (2014) Convenient one-pot formation of 2,3-dialdehyde cellulose beads via periodate oxidation of cellulose in water. Biomacromol 15:1928-1932

20. Li J, Wan Y, Li L, Liang H, Wang J (2009) Preparation and characterization of 2,3-dialdehyde bacterial cellulose for potential biodegradable tissue engineering scaffolds. Mater Sci Eng C 29:1635-1642

21. Silva DM, Nunes C, Pereira I, Moreira AS, Domingues MRM, Coimbra MA, Gama FM (2014) Structural analysis of dextrins and characterization of dextrin-based biomedical hydrogels. Carbohyd Polym 114:458-466

22. Wei J, Du C, Liu H, Chen Y, Yu H, Zhou Z (2016) Preparation and characterization of aldehyde-functionalized cellulosic fibers 
through periodate oxidization of bamboo pulp. BioResources 11:8386-8395

23. Yang H, Alam MN, van de Ven TG (2013) Highly charged nanocrystalline cellulose and dicarboxylated cellulose from periodate and chlorite oxidized cellulose fibers. Cellulose 20:1865-1875

24. Fahim AM, Shalaby MA, Ibrahim MA (2019) Microwave-assisted synthesis of novel 5-aminouracil-based compound with dft calculations. J Mol Struct 1194:211-226

25. Mohammadi MK (2013) Microwave-assisted oxidation of organic compounds with cetyltrimethylammonium chlorochromate. J Synth Theory Appl 2:87-90

26. Mekheimer RA, Hilmy NM, Hameed AA, Dacrory S, Sadek KU (2011) Simple, three-component, highly efficient green synthesis of thiazolo [3, 2-a] pyridine derivatives under neat conditions. Synth Commun 41:2511-2516

27. Ali A, Ganie SA, Mazumdar N (2018) A new study of iodine complexes of oxidized gum arabic: an interaction between iodine monochloride and aldehyde groups. Carbohyd Polym 180:337-347

28. Guo J, Ge L, Li X, Mu C, Li D (2014) Periodate oxidation of xanthan gum and its crosslinking effects on gelatin-based edible films. Food Hydrocoll 39:243-250

29. Mou K, Li J, Wang Y, Cha R, Jiang X (2017) 2,3-dialdehyde nanofibrillated cellulose as a potential material for the treatment of MRSA infection. J Mater Chem B 5:7876-7884

30. Zaaba N, Foo K, Hashim U, Tan S, Liu W-W, Voon C (2017) Synthesis of graphene oxide using modified hummers method: solvent influence. Proc Eng 184:469-477

31. Dacrory S, Moussa M, Turky G, Kamel S (2020) In situ synthesis of $\mathrm{Fe}_{3} \mathrm{O}_{4} @$ cyanoethyl cellulose composite as antimicrobial and semiconducting film. Carbohyd Polym 236:116032

32. Dacrory S, Fahim AM (2020) Synthesis, anti-proliferative activity, computational studies of tetrazole cellulose utilizing different homogenous catalyst. Carbohyd Polym. https://doi.org/10.1016/j. carbpol.2019.115537

33. Dacrory S, Abou-Yousef H, Abou-Zeid RE, Kamel S, Abdel-Aziz MS, Elbadry M (2018) Preparation and characterization of ecofriendly carboxymethyl cellulose antimicrobial nanocomposite hydrogels. J Renew Mater 6:536-547

34. Huang R, Liu Z, Sun B, Fatehi P (2016) Preparation of dialdehyde cellulose nanocrystal as an adsorbent for creatinine. Can J Chem Eng 94:1435-1441
35. Keshk SM, Ramadan AM, Bondock S (2015) Physicochemical characterization of novel schiff bases derived from developed bacterial cellulose 2, 3-dialdehyde. Carbohyd Polym 127:246-251

36. Anjali T (2012) Modification of carboxymethyl cellulose through oxidation. Carbohyd Polym 87:457-460

37. Mehdaoui R, El Ghali A, Cheikhrouhou W, Beyou E, Baouab MHV (2017) Fe 3 o 4 nanoparticles coated by new functionalized tetraaza-2, 3 dialdehyde micro-crystalline cellulose: synthesis, characterization, and catalytic application for degradation of acid yellow 17. Iran Polym J 26:597-613

38. Ghanem AF, Badawy AA, Mohram ME, Rehim MHA (2020) Synergistic effect of zinc oxide nanorods on the photocatalytic performance and the biological activity of graphene nano sheets. Heliyon 6:e03283

39. Ghanem AF, Youssef AM, Rehim MHA (2020) Hydrophobically modified graphene oxide as a barrier and antibacterial agent for polystyrene packaging. J Mater Sci 55:4685-4700

40. Yadav M, Rhee K, Jung I, Park S (2013) Eco-friendly synthesis, characterization and properties of a sodium carboxymethyl cellulose/graphene oxide nanocomposite film. Cellulose 20:687-698

41. Venkateshan M, Muthu M, Suresh J, Ranjith KR (2020) Azafluorene derivatives as inhibitors of sars COV-2 RDRP: synthesis, physicochemical, quantum chemical, modeling and molecular docking analysis. J Mol Struct 1220:128741

42. Fahim AM, Shalaby MA (2019) Synthesis, biological evaluation, molecular docking and dft calculations of novel benzenesulfonamide derivatives. J Mol Struct 1176:408-421

43. Farag AM, Fahim AM (2019) Synthesis, biological evaluation and dft calculation of novel pyrazole and pyrimidine derivatives. J Mol Struct 1179:304-314

44. Mahmood A, Akram T, de Lima EB (2016) Syntheses, spectroscopic investigation and electronic properties of two sulfonamide derivatives: a combined experimental and quantum chemical approach. J Mol Struct 1108:496-507

45. Das MR, Sarma RK, Saikia R, Kale VS, Shelke MV, Sengupta P (2011) Synthesis of silver nanoparticles in an aqueous suspension of graphene oxide sheets and its antimicrobial activity. Colloids Surf B 83:16-22

Publisher's Note Springer Nature remains neutral with regard to jurisdictional claims in published maps and institutional affiliations. 